\title{
Aquaculture Sustainability Dilemmas
}

\author{
Mavraganis T* \\ Theodoros Mavraganis, TEI of Western Greece Research Team, Greece \\ *Corresponding author: Theodoros Mavraganis, TEI of Western Greece Research Team, \\ Profiti Ilia 3, Agioi Theodoroi Corinthias, 20003 Greece, Tel: +306946941762; \\ Email: theodore1978@gmail.com
}

\section{Opinion Article}

Volume 2 Issue 4

Received Date: July 10, 2018

Published Date: July 17, 2018

DOI: $10.23880 /$ jenr-16000138

\section{Opinion}

The most important issue in all agricultural activities nowadays is how to produce more and rapidly. The same applies to aquaculture, especially as a growing activity during the last decade. The producers and scientists involved in aquaculture lead to enhance and develop the methodology quickly, and that has been progressed by the latest figures, which show aquaculture to be one of the main sources of human food for the next decades. The aquaculture production has been urgent since the food resources have been reduced not only by human growing population but also due to the climate change which is happening already.

However, questions arise over this approach. Is this production going to be sustainable in the future or it will follow the rest of the agricultural development which led to environmental and also medical issues over the human health. Will aquaculture production will be ethical towards the rest of the ecological resource and its consuming users or no need to address these issues, while the population is so large and keeps on rising? Is this high production due to making profit only, is the ethical responsibility of the producers and scientists to provide all the necessary product for the current and growing human population?

With the research being high in the field, new technologies will be introduced and new innovative approaches will provide higher production levels. With this, the profit will come and the production will thrive in amount. The sustainability is often used as a definition and wish, but less as application and practise. The majority of the used legislation is outdated today, as the climate change issues were not considered back then and thus not included. This is still a conflict within the global, as more legislators and few scientists reject the climate change as a substantial phenomenon, delaying the mitigation of the phenomenon and worsen it instead. The eventual rise of the temperature on the planet surface will consequence the terrestrial farming in significant methodology alteration, but this may not happen in the marine environment due to the attribute of the water mass resistance to high-temperature alterations and thus the marine farming will continue to grow practically untouched.

The Sustainability of the aquaculture production won't necessarily mean the reduction of the fish biomass. There are two issues to consider: the evenly distributed farming in spatial terms and the research for the prospect to farm new marine species. Especially if the two combined. Looking at the statistics concerning the global production, the core of the farming is observed to be highest in only one continent and in closed sea areas.

The uneven production leads to local pollution, but when the production is spread according to the carrying capacity of the ecosystems, the pollution is much less and the farming on the far open sea tend to decrease the impacts quicker. With the current population growth rate, the new sea platform industry will be the fish farming. Furthermore, the production is conventional around a significant number of fish species and new species farming innovation has left behind. By farming the same fish continuously the research is focused on these species and the possibility to discover a new trend or 


\section{Journal of Ecology \& Natural Resources}

methodology in fish farming is radically minimised. Thus, sustainability will need more innovative and hypothetical based scientific research as well as more new space to grow.

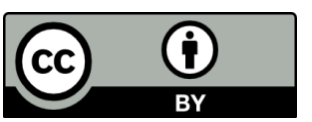

